\title{
Results of lateral pin fixation for the displaced supracondylar fracture of humerus in children
}

\author{
H.K. Gupta ${ }^{1}$, K.D. Khare ${ }^{2}$, D. Chaurasia ${ }^{3}$ \\ ${ }^{1}$ Lecturer, ${ }^{2}$ Professor, ${ }^{3}$ Resident Department of Orthopaedics, College of Medical Sciences, Teaching Hospital, Bharatpur, \\ Nepal
}

\begin{abstract}
Supracondylar fracture is common fracture in children and choice of treatment in displaced fracture is closed reduction and percutaneous pinning. There are different methods of fixation techniques described and practiced. This study was undertaken to evaluate the results of lateral pin fixation for the displaced supracondylar fracture of humerus in children.

25 children with displaced Supracondylar fracture were treated with closed reduction and percutaneous lateral fixation by two K-wires. Above elbow slab applied for 4 weeks (mean 28.4 days \pm SD 2.27) followed by physiotherapy and were followed for mean of 73.24 days( \pm SD 3.66 days). The Flynn's grading system was used to evaluate functional and cosmetic outcome. Loss in Baumann's angle was measures.
\end{abstract}

All the patient had satisfactory outcome with excellent to good grading as per Flynn's criteria. The mean Baumann's angle loss was 5.52 degrees( $\mathrm{SD} \pm 1.75)$. Two pin tract infections noted which responded to oral cloxacillin for 5 days. No neurovascular or serious complication noted.

In view of results obtained, lateral $\mathrm{K}$-wire fixation provided good fracture stability, good union and satisfactory outcome with minimal complication and virtually no iatrogenic nerve injury.

Key words: Supracondylar humerus fracture, lateral pin fixation, iatrogenic nerve injury.

\section{Introduction}

Supracondylar fractures of the humerus are the most common fracture to occur around elbow in children and sometimes can be challenging to treat. They account for $75 \%$ of all elbow fractures. ${ }^{1}$ There are many treatment modalities available to treat such fractures with different outcomes but closed reduction and percutaneous pinning is the treatment of choice in Correspondence: H. K. Gupta E-mail:hmntkg@yahoo.com displaced Supracondylar fractures. Because of difficulty in maintaining reduction in plaster, operative reduction and pin fixation has become recommended practice. ${ }^{2}$ There have been numerous pinning techniques described in the literature. Swenson ${ }^{3}$, Flynn et $\mathrm{al}^{4}$ and Nacht et $\mathrm{al}^{5}$ have used two crossed pins inserted from medial and lateral epicondyles. But this techniques carries the risk of iatrogenic ulnar nerve palsy during insertion of medial pin with reported incidence of 4.3 times higher than with lateral pinning. ${ }^{6}$ 
The optimal pinning technique providing adequate stability and avoiding iatrogenic nerve injury has been the subject of discussion. Arino et $\mathrm{al}^{7}$ has described lateral pinning technique avoiding medial pin insertion and Dorgan's method which has two crossed wires put laterally. ${ }^{8}$ There had been continuous debate regarding stability of fracture fixation after different configuration of pinning methods. The stability of crossed pinning method is biomechanically more stable but again carries the risk of nerve injury. ${ }^{9,10}$ The aim of this study was to evaluate the results of lateral pin fixation for the displaced supracondylar fracture of humerus in children.

\section{Materials and methods}

The design of this study was prospective observational study. Between August 2009 to July 2010, 25 cases with displaced Supracondylar fracture were considered in the study. Those with compound fracture, floating elbow, vascular injuries that required repair and those that required open reduction were also not taken into study. Demographic information was collected from each patient including age, sex, mode of injury and injured side. The fractures were classified according to Wilkins modification of Gartland classification. ${ }^{11}$ All the patients were evaluated preoperatively routinely for any neurovascular deficit and required investigations for pre-anaesthetic clearance. General anaesthesia was used for all cases and fractures were reduced by closed method. The maneuver used was traction to the fractured limb with elbow in 20 degree flexion with counter traction at arm, gradual correction of rotation and mediolateral shift and then flexing elbow with pressure on olecranon to correction posterior shift. Pronation of forearm and hyperflexion done and reduction checked on $\mathrm{C}$-arm in anteroposterior, lateral and two oblique planes. If reduction is acceptable, straping of forearm with arm done in the same position with cotton bandage. Two K- wires were then inserted under C-arm guidance from lateral epicondyle towards medial cortex of the proximal fragment with the attempt to put the pins in maximal separation at fracture site and divergent direction 9 (Fig. 1, fig. 2). K-wires were bent outside the skin and cut and above elbow slab applied. Preoperatively single dose of ceftriaxone was given as prophylactic antibiotics, dose adjusted to their weight. The patients were called after one week for check x-ray for any displacement and after four weeks for removal of slab, check x-ray and removal of kwires followed by physiotherapy for elbow. The patient was then followed up 3 weekly with clinical and radiographic evaluation for Baumann's angle loss. The clinical outcome was measured as per criteria of Flynn et $\mathrm{al}^{4}$ (Table 1).

Table: 1. Flynn et al. criteria for grading ${ }^{4}$

\begin{tabular}{lccc}
\hline Results & Rating & $\begin{array}{c}\text { cosmetic factor: } \\
\text { carrying angle loss(degrees) }\end{array}$ & $\begin{array}{c}\text { Functional factor: } \\
\text { Motion loss(degrees) }\end{array}$ \\
\hline Satisfactory & Excellent & $0-5$ & $0-5$ \\
& Good & $5-10$ & $5-10$ \\
Unsatisfactory & Fair & $10-15$ & $10-15$ \\
\hline
\end{tabular}

Statistical analyses were made with the help of SPSS version 18. The results were tabulated as frequency distribution for qualitative values and arithmetic mean and standard deviation derived for quantitative variables. 
H.K. Gupta, Results of lateral pin fixation for the displaced supracondylar fracture of humerus in children

\section{Results}

25 cases of displaced Supracondylar fracture (type III) were treated with lateral pinning. There were 16 males (64\%) and 9 females (36\%). Their age ranged from 3-12 yrs (median age6 yrs). Most of the injuries occurred on left side (60\%) and the commonest mode of injury was fall while running in 15 cases (60\%). Other mode of injuries was fall from height in 7 cases $(28 \%)$ and Road traffic accident in 3 cases (12\%). None of them had any neurological or vascular deficit and all were managed within $24 \mathrm{hrs}$ of presentation to the hospital. Closed reduction was successful in all cases and was discharged from hospital in 1-2 days. Slab removed at an average of 4 weeks(mean 28.4 days,SD2.27). The physiotherapy started immediately after removal of slab and K-wires. The mean follow up duration was 73.24 days (SD3.66). At final follow up the range of movement and grading was done as per Flynn's criteria. The results were as in Table 2. Radiograph of both the elbows were also taken for determining any loss of Baumann's angle.

Table: 2. Final Results of lateral K- wire fixation of supracondylar fracture humerus.

\begin{tabular}{lccccc}
\hline Results & $\begin{array}{c}\text { Flynn's } \\
\text { grading }\end{array}$ & $\begin{array}{c}\text { Cosmetic factor } \\
\text {-loss of carrying } \\
\text { angle (degrees) }\end{array}$ & $\begin{array}{c}\text { Outcome } \\
\text { of } \\
\text { patients }\end{array}$ & $\begin{array}{c}\text { Functional } \\
\text {-loss of movement } \\
\text { (degrees) }\end{array}$ & $\begin{array}{c}\text { Outcome } \\
\text { of } \\
\text { Patient }\end{array}$ \\
\hline Satisfactory & Excellent & $0-5$ & $17(68 \%)$ & $0-5$ & $18(72 \%)$ \\
Satisfactory & Good & $6-10$ & $8(32 \%)$ & $6-10$ & $7(28 \%)$ \\
Satisfactory & Fair & $11-15$ & 0 & $11-15$ & 0 \\
Unsatisfactory & poor & $>15$ & 0 & $>15$ & 0 \\
\hline
\end{tabular}

All the patients had satisfactory results functionally and cosmetically. 17(68\%) patients had excellent grading and $8(32 \%)$ had good grading. 18 patients $(72 \%)$ had less than 5 degrees loss of range of movement whereas $7(28 \%)$ patients had loss of movement 10 degrees and graded as good. None had fair or poor graded results. The average loss of carrying angle was 7 degrees (SD3.60). The mean loss of Baumann's angle was 5.52 degrees (SD1.75).Two patients had pin tract infection, but they responded well to 5 days course of oral cloxacllin. None required re-manipulation and no neurovascular deficit encountered. All fractures united well.
Fig-1: Pre operative $x$-ray of the fracture supracondylar of the humerus
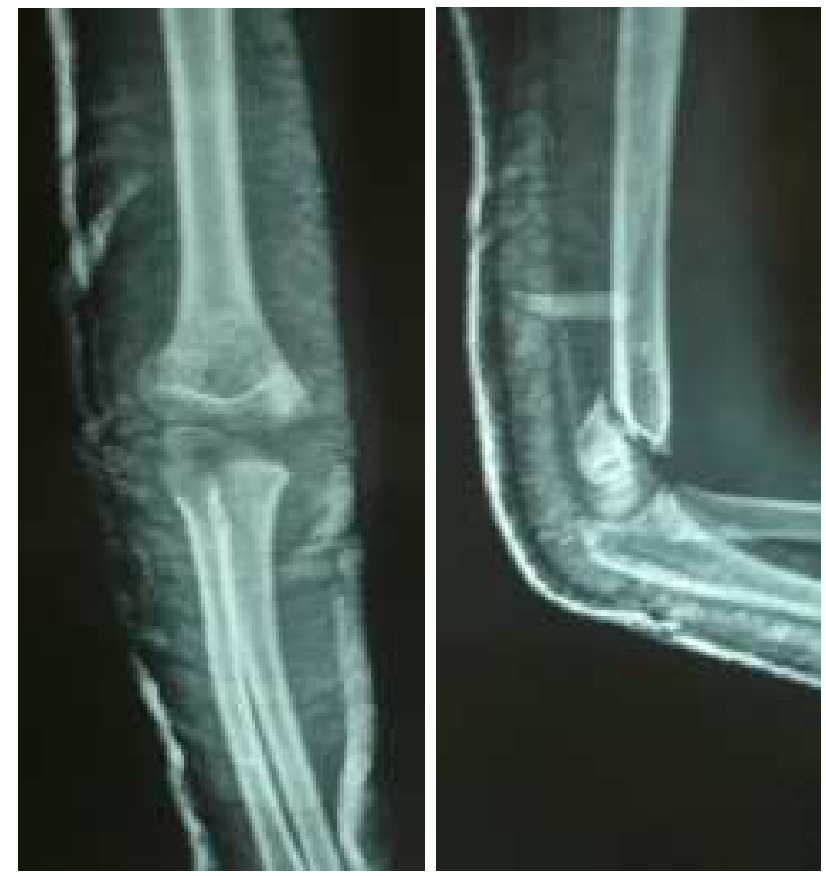
Fig-2: Post operative x-ray of the fracture supracondylar of the humerus

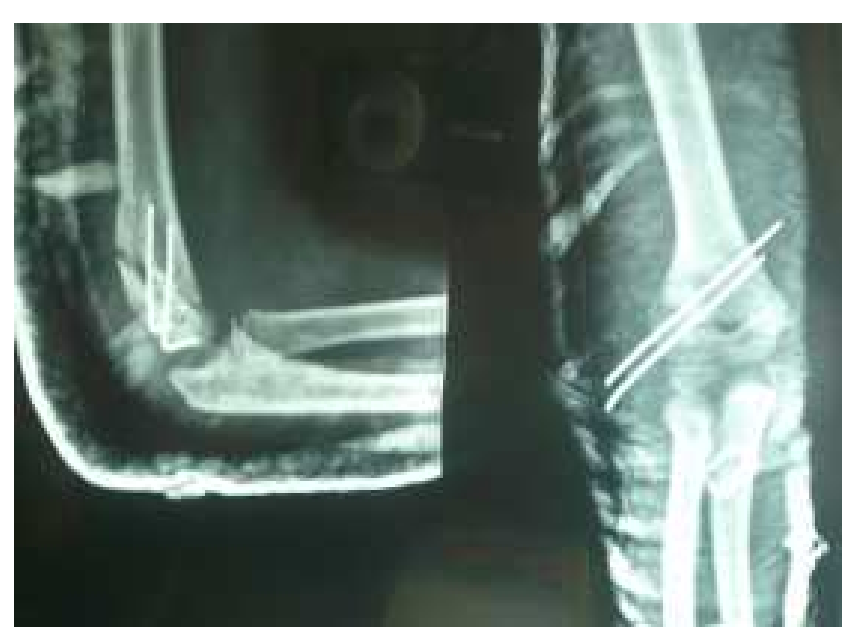

\section{Discussion}

The supracondylar fracture of the humerus is commonest in elbow injuries accounting for $75 \%$ of all elbow fractures. Optimal fracture fixation construct should be able to prevent displacement at the fracture site, avoid postoperative deformity which is as high as $17 \%$ after various mode of fixation. ${ }^{2}$ Biomechanical studies have shown that cross pinning are more resistant to torsional strength than lateral pinning but carries a greater risk of iatrogenic ulnar nerve injury. However in the literature, some cases of iatrogenic nerve injuries have been documented in lateral pinning. ${ }^{12}$ Several authors instead, recommend lateral pinning as iatrogenic nerve injury was rare. ${ }^{13}$ Three lateral pins are recommended in older children ${ }^{14}$, but the use of $3^{\text {rd }}$ pin will enter through joint and create crowding, hence more chance of infection is there ${ }^{15}$. Two pins used with adequate precaution in divergent fixation have as good results, hence we preferred two lateral pins. In this study, all the cases had excellent or good results with respect to cosmetic factor or functional factor. Pin tract infection was also in only two cases, consistent with findings of others. ${ }^{8}$

\section{Conclusion}

In view of the obtained results and review of the literature, the two lateral $\mathrm{K}$-wires fixation in divergent fashion provided good fracture stability, good union rate with excellent functional and cosmetic outcome with minimum complication rate and virtually no iatrogenic nerve injury in management of displaced supracondylar fracture of humerus in children.

\section{References}

1. D. Skaggs, J. Pershad. Pediatric elbow trauma. Pediatric Emergency Care 1997; 13: (6) 425-34.

2. R. omid, P. D. Choi, D. L. Skaggs. Supracondylar humeral fracture in children. Journal of Bone and Joint Surgery 2008; 90: (5) 1121-32.

3. A. L. Swenson. Treatment of supracondylar fractures of the humerus by Kirschner wire trans-fixation. J Bone Joint Surg Am 1948; 30:993-7

4. J. C. Flynn, J.G. Mathews, R.L. Benoit. Blind pinning of displaced supracondylar fractures of the humerus in children. J Bone Joint Surg Am 1974; 56: 263-73

5. J. L. Nacht, M. L. Eker, S. M. K. Chug et al. Supracondylar fracture of the humerus in children treated by closed reduction and percutaneous pinning. Clin Orthop Relat Res 1983; 177:203.

6. P. Woratanarat. Cross pinnng for Supracondylar humerus fracture in children carries risk of iatrogenic ulnar nerve injuries. J Orthop Trauma 2011; doi: 097/ BOT.0b013e3182de0.

7. V. C. Arino, E. E. Lluch, A.M. Ramirez et al. Percutaneous fixation of supracondylar fractures of the humerus in children. J Bone Joint Surg Am 1997; 59: 914. 
H.K. Gupta, Results of lateral pin fixation for the displaced supracondylar fracture of humerus in children

8. F. J. Shannon . Dorgan's percutaneous lateral cross wiring of supracondylar fractures of the humerus in children. J Pediatr Orthop 2004; 24: 376-9.

9. J. P. Lyons, E. Ashley, M. M. Hoffer. Ulnar nerve palsies after percutaneous cross-pinning of supracondylar fractures in children's elbows. Journal of Pediatric Orthopaedics 1998; 18 (1): 43-5.

10. D. L. Skaggs, J.M. Hale, J. Bassett et al. Operative treatment of supracondylar fractures of the humerus in children: the consequences of pin placement. Journal of Bone and Joint Surgery 2001; 83 (5): 735-40.

11. K. E.Wilkins. Fractures and dislocations of the elbow region. In: Fractures in Children, C. A. Rockwood, K. E.Wilkins, R. E. King: $3^{\text {rd }}$ edi. Philadelphia, USA. JB Lippincott; 1984: 540-1.
12. S. A. Shamsuddin, R. Penafort, I. Sharaf. Crossedpin versus lateral-pin fixation in pediatric Supracondylar fractures. The Medical Journal of Malaysia 2001; 56: $38-44$.

13. J. E. Gordon, C.M. Patton, S. J. Luhmann et al. Fracturestability after pinning of displaced supracondylar distal humerus fractures inchildren. $J$ Pediatr Ortho p. 2001; 21: 313-8.

14. W. N. Sankar, N. M. Hebela, D. L. Skaggs et al. Loss of pin fixation in displaced supracondylar humeral fractures in children: causes and prevention. J Bone Joint Surg 2007; 89: 713-7.

15. Y. Ozturkmen, . Karamehmtoglu, I. Azboy. Closed reduction and percutaneous lateral pin fixation in the treatment of displaced Supracondylar fracture of the humerus in children. Acta Orthop Traumatol Turc 2005; 39(5): 396-403. 